\title{
OPTIMIZING THE DESIGN OF A HOLDER IN Metal AdDitive ManUfaCtURING
}

\author{
Jindrich Farsky, Milan Dana \& Ivana Zetkova
}
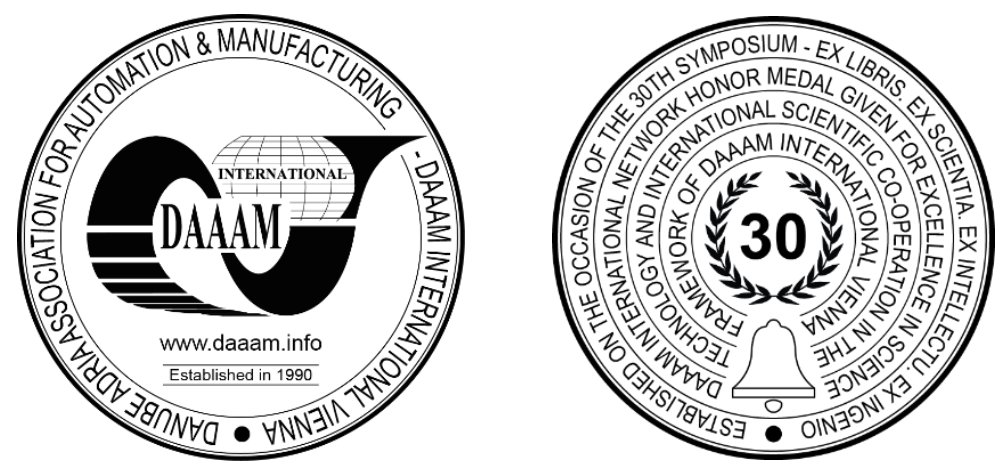

This Publication has to be referred as: Farsky, J[indrich]; Dana, M[ilan] \& Zetkova, I[vana] (2020). Optimizing the Design of a Holder in Metal Additive Manufacturing, Proceedings of the 31st DAAAM International Symposium, pp.0463-0466, B. Katalinic (Ed.), Published by DAAAM International, ISBN 978-3-902734-29-7, ISSN 1726-9679, Vienna, Austria

DOI: $10.2507 / 31$ st.daaam.proceedings.065

\begin{abstract}
Additive technologies have given us a new approach to designing because we can create very complex shapes that cannot be achieved with conventional machining methods. Also, using additive technologies provides us with the possibility of weight reduction while maintaining the rigidity of components or, as it is known, topological optimization. This article focuses on the design optimization of a steel holder used for holding a $4 \mathrm{~kg}$ tube. Basic topological software is used for the design optimization that allows us to achieve very quickly a view of the final shape of the component. This article describes the steps from the basic design to the final shape of the holder which was printed by DMLS technology on an EOS M290 printer.
\end{abstract}

Keywords: Additive Manufacturing; Topology Optimization; Holder; Design; Printing

\section{Introduction}

Additive manufacturing, also known as 3D printing technology, is a technique that is used to build up components (products) layer by layer from virtual models (created in CAD). This technology has seen unprecedented growth as a manufacturing tool. Additive manufacturing can be used as a tool for reducing the weight of components, creating special shapes of surfaces, and new shapes of inner structures such as cooling channels, lattice structures, etc. One of the methods used in additive manufacturing is topological optimization, which serves to reduce weight while maintaining the requirements which are placed on the products. This means we can build products with lower weights with the same properties as the solid parts. It leads to shortening the build time, minimizing the material used for printing and also cutting the cost of the products. It has found applications in many sectors such as the aircraft, aerospace and automotive industries. It is also a great tool for academic research. [1], [2], [3]

One of the most widely used methods for weight reduction while maintaining stiffness or even improving stiffness in additive manufacturing is topology optimization. It is used to find the optimum way for omitting the largest amount of material while maintaining the stiffness of components. To do this it is necessary to know the basic design of the components, constraints, loads and boundary conditions, as seen in Fig. 1., which shows the basic use of topology optimization on a beam with a prescribed volume constraint which is loaded by a force. [4], [5], [6] 


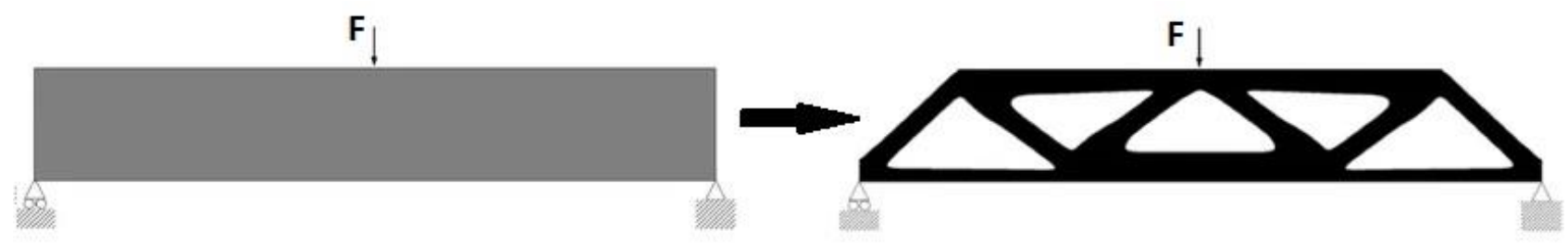

Fig. 1. The typical use of topology optimization [7]

Today's world allows us to use a lot of software to conduct topology optimization on products. This software can be very complex, but it achieves very accurate results which match real values. However, each simulation is very difficult to prepare, both in terms of knowledge and time. Fortunately, there is software on the market that is very simple, and the results are sufficient for a lot of basic changes in the design of products. Their use is very simple and intuitive, and the required result can be achieved in a moment. The main aim of this work is to show how it be possible to use software Inspire for topology optimization on the selected part, which will be manufactured by 3D metal printing technology. Also, the intention of this article is to verify how much difficulty and useable is using this software for 3D printing parts.[8]

\section{Specification of the printed part}

The task assignment was very simple. It was necessary to optimize the design of a component which has a solid construction with maximum use of topology optimization software and thereby create a new design which is able to hold a force of $40 \mathrm{~N}$ with a centre of action $50 \mathrm{~mm}$ from an aluminium $\mathrm{X}$ profile to which the component is attached so that there will be no deformation of the component by bending. An M10 screw and nut is used for the connection between the component and the aluminium X profile. A sketch with the load and the component in the default state is shown in Fig. 2. (left).
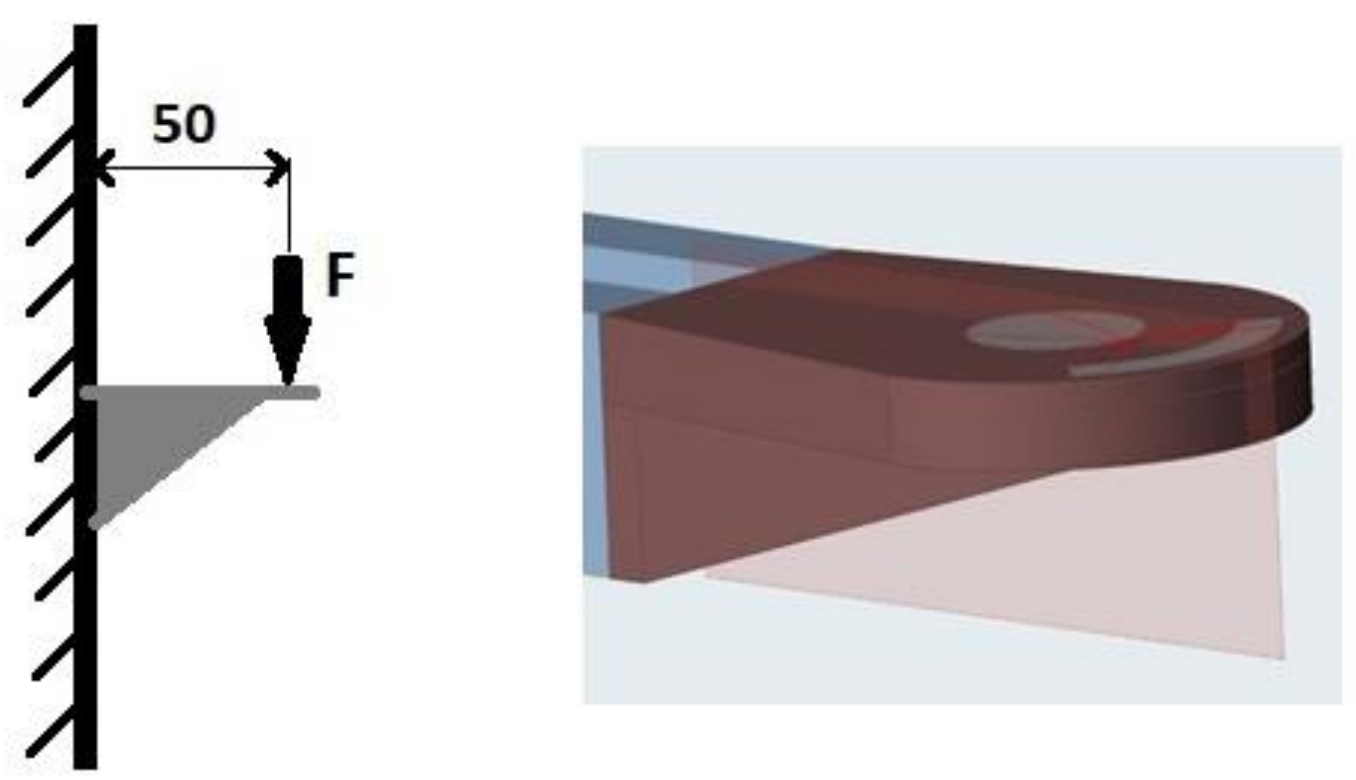

Fig. 2. Specification and parameters of the experiment

\section{Topology optimization of the part}

The first step is to specify all the loads and connection of the component. Also, it is necessary to define which parts of the component can be changed by topology optimization. This step is shown in Fig. 2. On the left is shown the location of the $40 \mathrm{~N}$ force, then on the right the definition of the rebuilt parts of the component (brown), and aluminium $\mathrm{X}$ profile (blue). This all thing is necessary to set up in the program and it was necessary to select how much is possible to remove the material from the removable structure (brown). This setting will affect the overall stiffness of the part; therefore, it was necessary to select the right value. Fig 3 shows the result, where the brown part of the component is changed to the lighter version, where the best way for this load was using "sticks". These "sticks" are not applicable in this state. Therefore, it was necessary to edit each "stick" and make some inner edits so that the component is as light as possible. The inner relief was designed so that it can be printed without any support structures and there are holes in the bottom of the component for dumping the powder. The correct positioning and rotation of the component during the print process is related to this. The final shape of the prepared component for printing is shown in Fig. 3. on the right. 

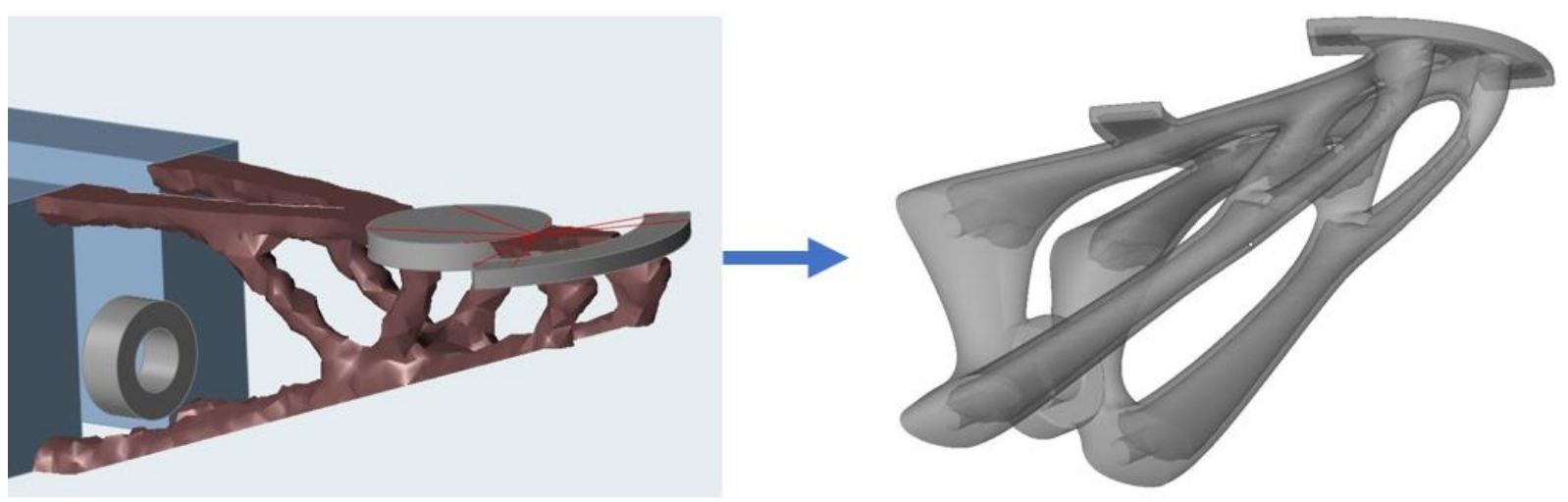

Fig. 3. Evolution of component from 'sticks' to final shape

After these steps, it was necessary to conduct a strength analysis using the finite element method to check if the component withstands the load and does not bend more than the allowed value. This was necessary to verify if the new shape of the component was created well. The maximum allowed bending value is $0.1 \mathrm{~mm}$. The result of FEM analysis is shown in Fig. 4. The result of FEM analysis is shown in Fig. 4. The value of bending is $6.953 \times 10^{-3}$ which is smaller than the allowed value. So, the size of the bend was evaluated as negligible. Therefore, it was possible to prepare the data for printing.

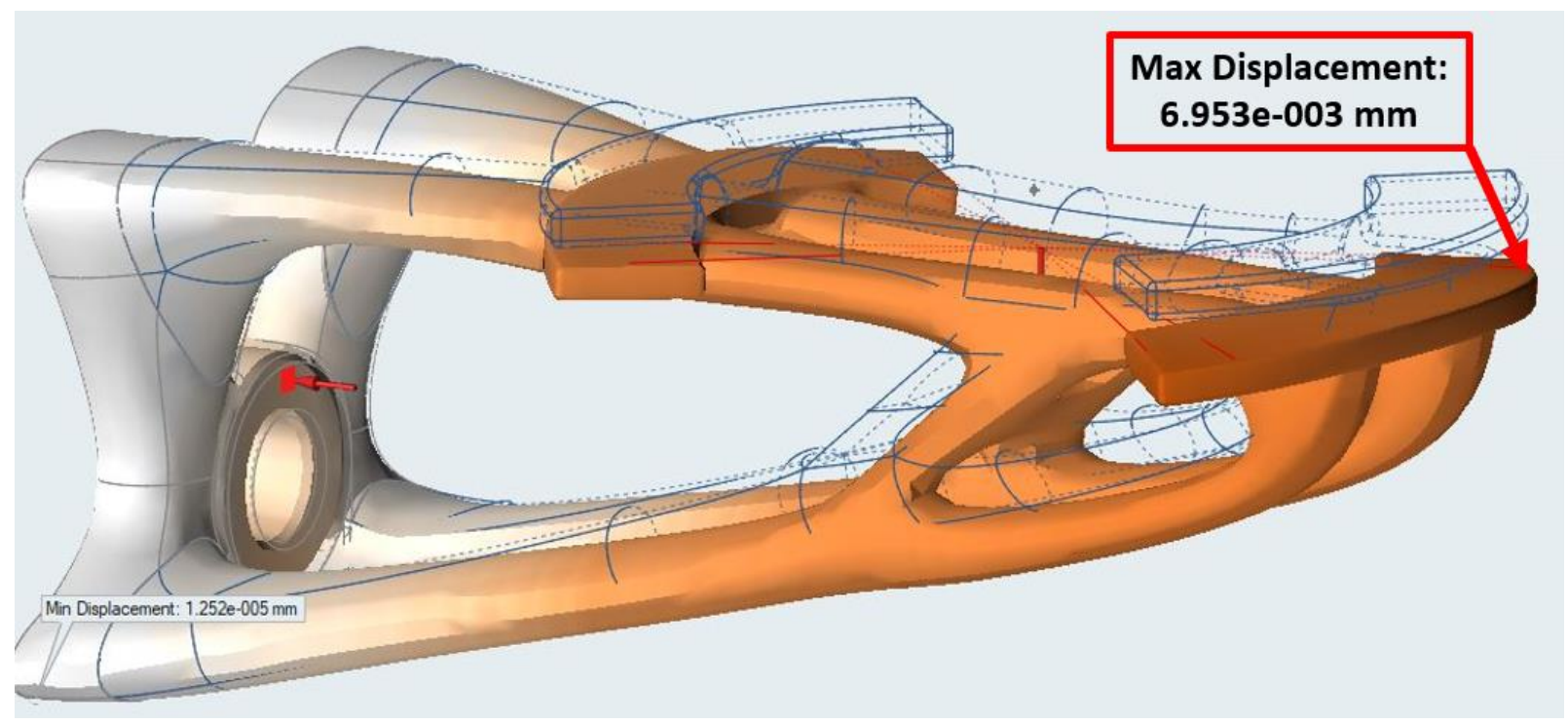

Fig. 4. FEM analysis

\section{Preparing the part for printing}

The first step of preparing the part for printing is to design the best way to print the part with the inner structure. The positioning of the part plays a big role in printing. Therefore, it is necessary to know which parts of the component are functional and which are only for construction. Also, it necessary to know if the components have an inner structure or are solid, and many more things. The positioning of the parts also affects how many support structures will be needed, how long the print will take, how difficult the post-processing will be (removal of support structures), etc.

From the previous steps, we know the component has a hollow inner structure, which was created so that it would not need support structures inside the part when the correct position is selected. Therefore, it was necessary to place the component in the $\mathrm{Z}$ axis as shown in Fig. 5.

The next step was to create the support structure which guarantees the connection between the part and the build platform. Also, support structures were created which secure the holding surfaces which have angles less than $44^{\circ}$. However, this leads to some supports being very long and thin, because the supported surfaces are very far from the build platform. The lower supports were reinforced by cones because these support structures could have been destroyed by the ceramic blade of the recoater. The higher supports were connected to the parts, because they were very long and thin when they were connected to the build platform. The support structures are shown in Fig. 5. The part was then printed on the EOS M290 of material MS1. The print was done with standard parameters of the process with a ceramic recoater blade. After successful printing, we can say that the positioning of the part and its supports were designed well. 

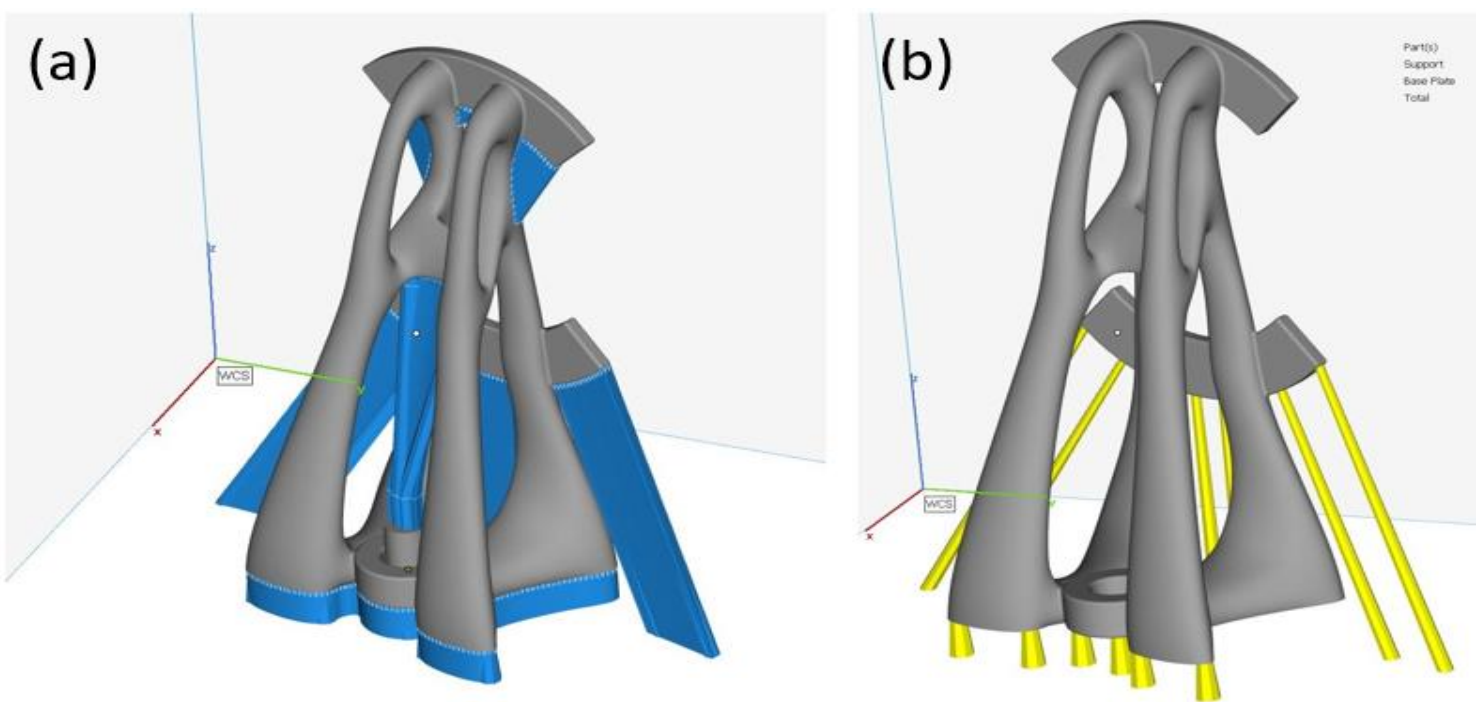

Fig. 5. Support structure: all supports (a), cone supports (b)

\section{Conclusion}

This article describes the rapid topological optimization of a component that serves as a rod holder and is attached to a wall as an embedded beam. First, the basic theory of topological optimization was briefly described and applied to a component. Subsequently, we described how topological optimization works and what is needed to know and do it. A component was also described which was selected for basic topological optimization of its shape. Another part of the work has already dealt directly with the application of topological optimization to selected components. At the same time, the steps taken to optimize the component were described. The last part of the work deals with preparing the data for printing a topologically optimized component and the steps required to guarantee the successful printing of this component. There was also an explanation of why support structures had to be reinforced. The component was printed using the DMLS method on an EOS M290 3D printer to verify its functionality. Also, we can say the software is very fast and easy to use for setting and make a good topology optimization of the part.

This topological optimization of parts serves as an input experiment for future research on this issue. In the future, it is expected that there will be an expansion of the knowledge database and software used for faster and more demanding topological optimizations because this step is only tested at one the part.

\section{Acknowledgments}

This paper was supported by the Internal Grant Agency of the University of West Bohemia, project No. SGS-2019-008 Research and Development for Innovation in the Field of Manufacturing Technology - Machining Technology III.

\section{References}

[1] F42 Committee, 'Terminology for Additive Manufacturing Technologies', ASTM International. doi: 10.1520/F2792-12A.

[2] M. Nozar, I. Zetkova, P. Hanzl, and M. Dana, 'A Customer's View on Key Aspects of Metal Additive Manufacturing', in DAAAM Proceedings, 1st ed., vol. 1, B. Katalinic, Ed. DAAAM International Vienna, 2017, pp. 0957-0966.

[3] S. Chekurov and N. Kretzschmar, 'Classification of End-Use Industrial Applications of Additive Manufacturing', in DAAAM Proceedings, 1st ed., vol. 1, B. Katalinic, Ed. DAAAM International Vienna, 2018, pp. 0894-0900.

[4] 'An aerospace bracket designed by thermo-elastic topology optimization and manufactured by additive manufacturing - ScienceDirect'. https://www.sciencedirect.com/science/article/pii/S1000936119303358 (accessed Mar. 26, 2020).

[5] J.-H. Zhu, W.-H. Zhang, and L. Xia, 'Topology Optimization in Aircraft and Aerospace Structures Design', Arch. Comput. Methods Eng., vol. 23, no. 4, pp. 595-622, 2016, doi: 10.1007/s11831-015-9151-2.

[6] 'Experimental validation and microstructure characterization of topology optimized, additively manufactured SS316L components - ScienceDirect'. https://www.sciencedirect.com/science/article/pii/S0921509320301386 (accessed Mar. 26, 2020).

[7] M. P. Bends?e and O. Sigmund, 'Topology optimization', in Optimization of Structural and Mechanical Systems, 0 vols, WORLD SCIENTIFIC, 2007, pp. 161-194.

[8] P. Hanzl, I. Zetkova, and M. Dana, 'A Comparison of Lattice Structures in Metal Additive Manufacturing', in DAAAM Proceedings, 1st ed., vol. 1, B. Katalinic, Ed. DAAAM International Vienna, 2017, pp. 0481-0485. 